
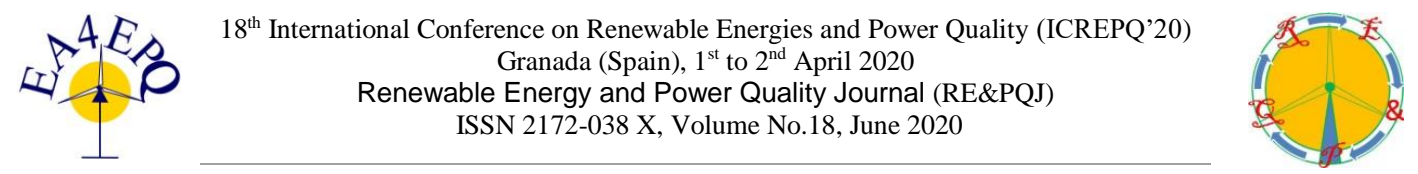

\title{
Experimental study of the physicochemical properties of new biofuels
}

\author{
A. Palomar-Torres ${ }^{1}$, E. Torres-Jiménez ${ }^{1}$, R. Bolaños-Jiménez ${ }^{1}$ and G. Bombek ${ }^{2}$ \\ ${ }^{1}$ Department of Mechanical and Mining Engineering, \\ EPSJ, University of Jaén, \\ Campus las Lagunillas s/n, A3, 23071 Jaén (Spain) \\ Fax number: +34953 212870, e-mail: apt00010@ @red.ujaen.es, etorres@ujaen.es, rbolanos@ ujaen.es
}

${ }^{2}$ Department of Process and Environmental Engineering, Faculty of Mechanical Engineering, University of Maribor, Smetanova ulica 17, SI-2000, Maribor (Slovenia)

Phone: +3862 220 7739, e-mail: gorazd.bombek@um.si

\begin{abstract}
In this work, some physical properties of several biofuels, which are used in compression ignition engines, of which no reference publications have been found, are experimentally obtained. These properties are essential when simulating engine processes such as injection and fuel spray. The measured properties are density and surface tension. Density is measured by the use of a pycnometer and surface tension by means of commercial equipment (Krüss-EasyDyne). Diesel fuel, biodiesel, as well as biodiesel-ethanol blends are tested. Density and surface tension are quantified, verifying that the density is proportional to the concentration of each fuel in the blend. Nevertheless, this is not the case of the surface tension, which fits a second-order polynomial.
\end{abstract}

Key words. Ethanol, Diesel, Biodiesel, Density, Surface tension.

\section{Introduction}

The emission of pollutants into the atmosphere, from the combustion of fossil fuels, is a problem that causes harmful effects on people's health. [1]

The most important harmful products emitted into the atmosphere are carbon monoxide (CO), carbon dioxide $\left(\mathrm{CO}_{2}\right)$, hydrocarbons $(\mathrm{HC})$, nitrogen oxides $\left(\mathrm{NO}_{\mathrm{x}}\right)$, particulate matter $(\mathrm{PM})$ and sulfur oxides $\left(\mathrm{SO}_{\mathrm{x}}\right)$. Levels of pollutants, $\mathrm{CO}_{2}$ emissions and fuel consumption of vehicles are approved following the Worldwide Harmonized Light Vehicles Test Procedure (WLTP, 2018). This new protocol was developed by the United Nations Economic Commission for Europe (UNECE) to replace the New European Driving Cycle (NEDC) as the European vehicle homologation procedure. The new European test procedure is more similar to the United States cycle (the Federal Test Procedure) [2].

Researchers use these standardized test procedures to determine the viability of new biofuels, as tested in the present paper [3].
Nowadays, approximately $95 \%$ of the energy required in the transportation sector comes from liquid fuels derived from petroleum and about $60 \%$ of this energy is used to manufacture fuels for transport. [4]

Over the last few years, many policies around the world have been imposed to reduce the negative effects of diesel engine emissions on people and the environment.

This paper focuses on obtaining some important properties of biofuels that will be useful for the appropriate study of injection systems to reduce diesel engine emissions and fuel consumption while, simultaneously, maintaining engine performance at an acceptable level.

For a long time, researches claim the importance of simulating processes concerning internal combustion engines in order to optimize engine performance and emissions [5], [6]. However, the development of these simulations is limited by the need for fuel properties information. This difficulty can be overcome by the experimental determination of these required properties.

Experimental data concerning the properties of fuels are essential for the construction of numerical models that simulate the fuel injection process [7] and the formation of the fuel spray inside the combustion chamber [8].

Furthermore, according to [9] a higher surface tension of the fuel also reduces the aerodynamic influence on the spray break-up. This fact also contributes to longer spray tip penetration. This can be explained by the KelvinHelmholtz instability model, where a higher surface tension of the fuel results in a higher surface tension force, which leads to smaller surface- instabilities (waves). This also contributes to smaller influence of the Bernoulli effect force. Consequently, sprays are longer and narrower. 
Knowing the value of the surface tension of a fuel is essential for the correct numerical simulation of the injection process and the subsequent fuel spray. This last process involves drops formation, which is determined by surface tension. This property is also essential when simulating the injection process since it significantly influences the phenomenon of cavitation.

CFD simulation of Diesel sprays is a difficult task due to the incomplete specification of initial conditions for the spray droplets, as well as for other reasons [10], [11]. This is mainly a consequence of lack of understanding of the atomization process in which the fuel breakup in droplets. This process is directly joined to surface tension property and influences the mechanisms that govern the spray formation

This paper deals with obtaining some properties of new biofuels that a simulation program requires for assisting in the development and optimization of internal combustion engines. To the knowledge of the authors, these properties cannot be obtained from a literature review. Specifically, the measured properties are: density and surface tension.

\section{Materials and Methods}

Initially, the tested fuels are obtained from expert companies in this field. Subsequently, the elaboration of the blends shown in Table I is performed.

According to the papers where fuel blends are tested in reciprocating engines, these blends are made on a volumetric basis since the Engine Control Unit (ECU) regulates the flow injected by volume and not by mass, as shown in the papers [12], [13].

Table I.- Fuels used (\% v/v)

\begin{tabular}{|c|c|c|c|}
\hline Nomenclature & $\%$ Ethanol & $\%$ Biodiesel & $\%$ Diesel \\
\hline E100 & 100 & 0 & 0 \\
\hline B100 & 0 & 100 & 0 \\
\hline D100 & 0 & 0 & 100 \\
\hline B75E25 & 25 & 75 & 0 \\
\hline B50E50 & 50 & 50 & 0 \\
\hline B25E75 & 75 & 25 & 0 \\
\hline
\end{tabular}

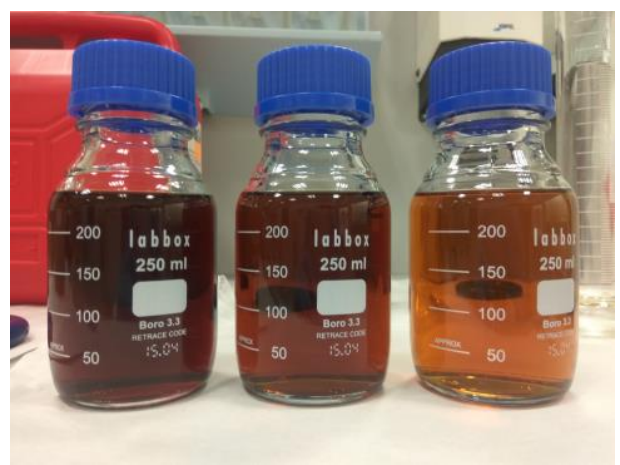

Fig. 1. Biodiesel-Ethanol blends

\section{A. Density}

To obtain the value of density for the fuels shown in Table I, a pycnometer (Figure 2) is used.
The measuring process consists of filling completely the pycnometer, avoiding the formation of bubbles inside. When closing, the fluid level will rise through the capillary and it will overflow, the capillary being also full. Finally, we will level out with the syringe to the calibration mark (Figure 2). A key issue in the pycnometer experimental process is the difficulty during the leveling out process, due to the formation of unwanted bubbles in the capillary.

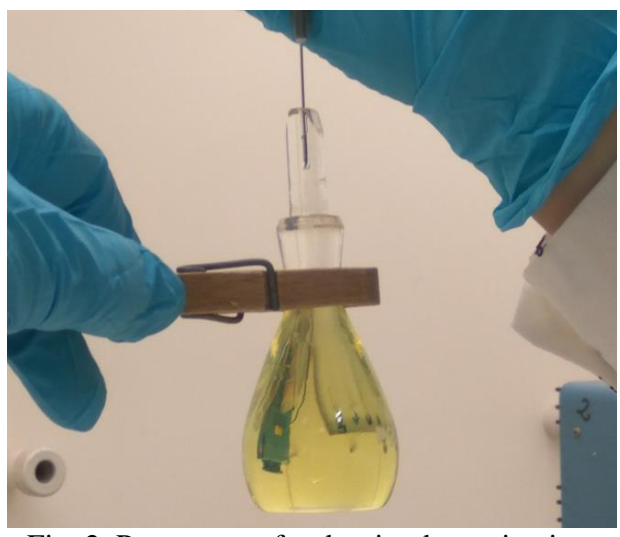

Fig. 2. Pycnometer for density determination.

A pycnometer is a device that enables a liquid's density to be measured accurately by reference to a reference fluid, such as water or mercury. In this case, the pycnometer used (POBEL) is calibrated at $20^{\circ} \mathrm{C}$. For this reason, it is not necessary to use a reference fluid. According to the calibration certificate of the pycnometer, its weight $\left(\mathrm{m}_{\mathrm{p}}\right)$ and volume $\left(\mathrm{V}_{\mathrm{p}}\right)$ are 29.1872 $\mathrm{g}$ and $24.629 \mathrm{ml}$, respectively. It is easy to calculate the density of the blend $\left(\rho_{\mathrm{d}}\right)$ as the ratio between the mass of the solution that is housed in the pycnometer $\left(\mathrm{m}_{\mathrm{d}}\right)$ and its volume $\left(\mathrm{V}_{\mathrm{p}}\right)$. On the other hand, the value of the mass of the sample $\left(\mathrm{m}_{\mathrm{d}}\right)$ will be the difference between the mass of the full pycnometer $\left(\mathrm{m}_{\mathrm{p}+\mathrm{d}}\right)$ and that of the empty pycnometer $\left(\mathrm{m}_{\mathrm{p}}\right)$, both masses are obtained experimentally using an analytical balance. Table III shows the density results obtained by applying Eq. (1).

$$
\rho_{d}=\frac{m_{d}}{V_{p}}=\frac{m_{p+d}-m_{p}}{V_{p}}
$$

Table II shows the average of 3 weights made for each sample.

Table II.- Mass of the full pycnometer $(\mathrm{g})$

\begin{tabular}{|c|c|}
\hline Fuel & $\mathrm{m}_{\mathrm{p}+\mathrm{d}}(\mathrm{g})$ \\
\hline E100 & 48.5402 \\
\hline B100 & 50.8079 \\
\hline D100 & 49.5279 \\
\hline B75E25 & 50.2612 \\
\hline B50E50 & 49.7416 \\
\hline B25E75 & 49.1894 \\
\hline
\end{tabular}

Authors like [14] and [15] have also used a pycnometer for density determination. In [14] this measurement procedure is applied to diesel fuel, biodiesel produced and its blends, obtaining very good results. In the case of 
authors like [15] apply this method to obtain the density of aqueous solutions of alkanolamines such as ATmethyldiethanolamine (MDEA) and 2-amino-2-methyl-1propanol (AMP), also with values very accurate.

\section{B. Surface tension}

The other property, surface tension, is measured by the EasyDyne tensiometer shown in Figure 3.

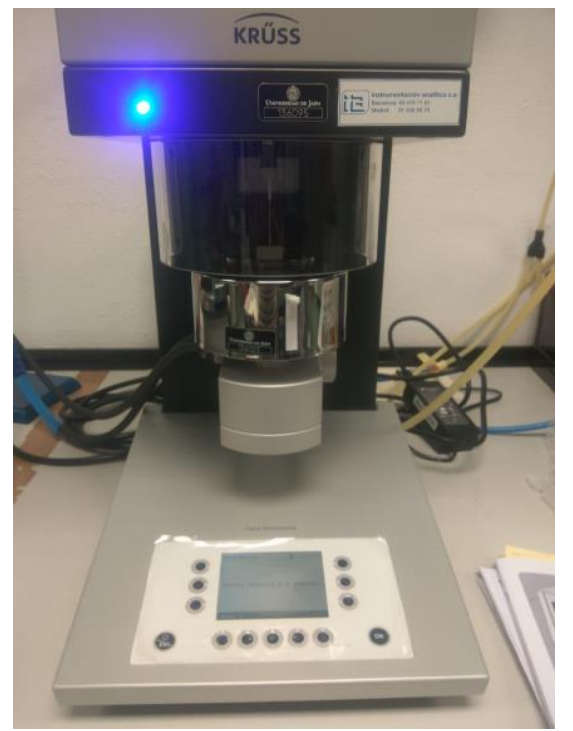

Fig. 3. EasyDyne tensiometer for surface tension determination

The measurement process in this equipment is quite simple. It consists of a plate (Figure 4) that is immersed in the different blends understudy, providing an average surface tension value $(\sigma(\mathrm{mN} / \mathrm{m}))$ over ten measurements. In addition, this equipment is very complete, since it also gives us the uncertainty of measurement $(\Delta \sigma(\mathrm{mN} / \mathrm{m}))$.

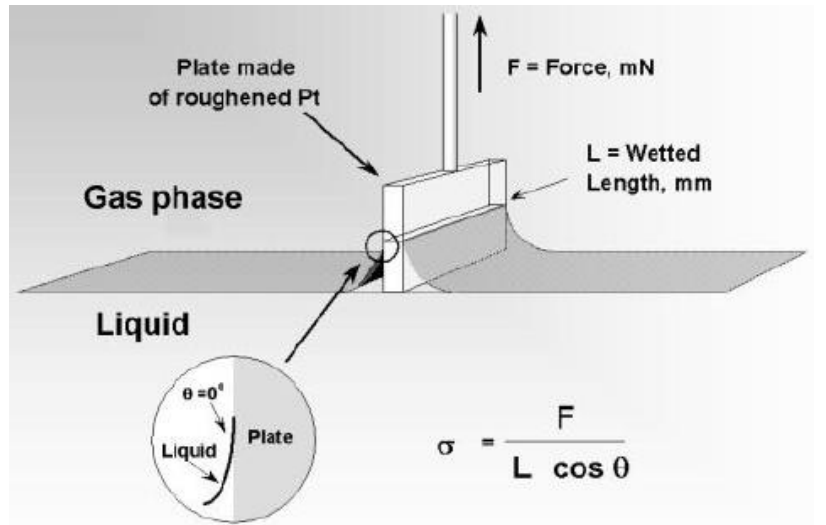

Fig. 4. Measuring plate [16]

It is important to note that both, the measuring plate and the container must be very clean and disinfected after taking the new measurement, since wastes from the previous test, which are adhered to the container wall, can make the next measure not to be accurate. Table III shows the surface tension results obtained by using the EasyDyne tensiometer.

Authors like [17] have used this tensiometer to measure many thermodynamic properties.

\section{Results}

The results obtained experimentally are shown in Table III.

Figure 5 represents the value of the density as a function of the biodiesel concentration, that is, it represents from $0 \%$ biodiesel (100E); 25B75E; 50B50E; 75B25E; up to $100 \%$ biodiesel (100B).

Table III.- Density and surface tension experimentally obtained for each fuel.

\begin{tabular}{|c|c|c|}
\hline & Density, $\rho,\left(\mathrm{kg} / \mathrm{m}^{3}\right)$ & $\begin{array}{c}\text { Surface tension, } \sigma, \\
(\mathrm{mN} / \mathrm{m})\end{array}$ \\
\hline Ethanol & 785.781 & 22.4 \\
\hline Biodiesel & 877.855 & 30.7 \\
\hline Diesel & 825.884 & 26.7 \\
\hline B75E25 & 855.655 & 26.7 \\
\hline B50E50 & 834.558 & 24.4 \\
\hline B25E75 & 812.138 & 23.4 \\
\hline
\end{tabular}

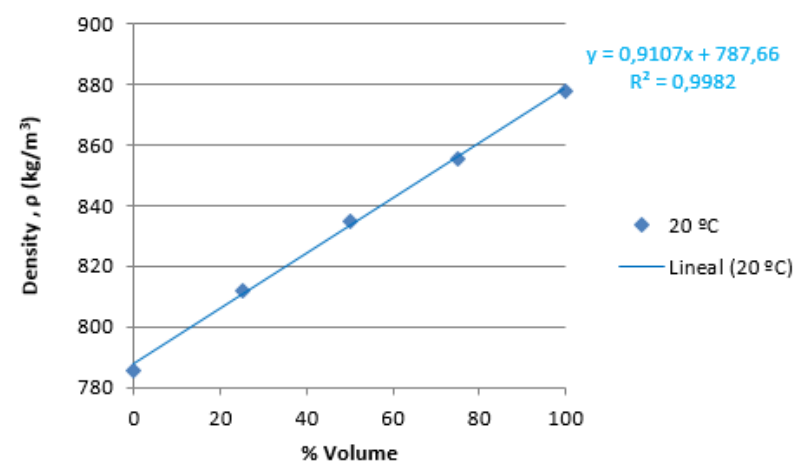

Fig. 5. Density $\left(\mathrm{kg} / \mathrm{m}^{3}\right)$ VS percentage by volume of biodiesel in the blend.

It is corroborated that the density of the blend is proportional to the concentration of each pure fuel in the blend as follows: the result of Eq. (2) is nearly the same as the result obtained experimentally (see the density of B75E25 in Table III). Table IV shows the results obtained by applying Eq. (2).

$$
\begin{aligned}
& 75 \% \rho_{B 100}+25 \% \rho_{E 100}=0.75 \cdot 877.855+ \\
& +0.25 \cdot 785.781=854.836
\end{aligned}
$$

Table IV.- Density of the blends obtained by linear fitting

\begin{tabular}{|c|c|}
\hline Blends & Density $\left(\mathrm{kg} / \mathrm{m}^{3}\right)$ \\
\hline B75E25 & 854.836 \\
\hline B50E50 & 831.818 \\
\hline B25E75 & 808.799 \\
\hline
\end{tabular}

Figure 6 shows the results obtained from surface tension. In addition, it is observed that these results fit quite accurately to a second-order polynomial, since $\mathrm{R}^{2}$ (coefficient of determination) is close to 1 , so the values do not follow a linear trend as in the case of density. 


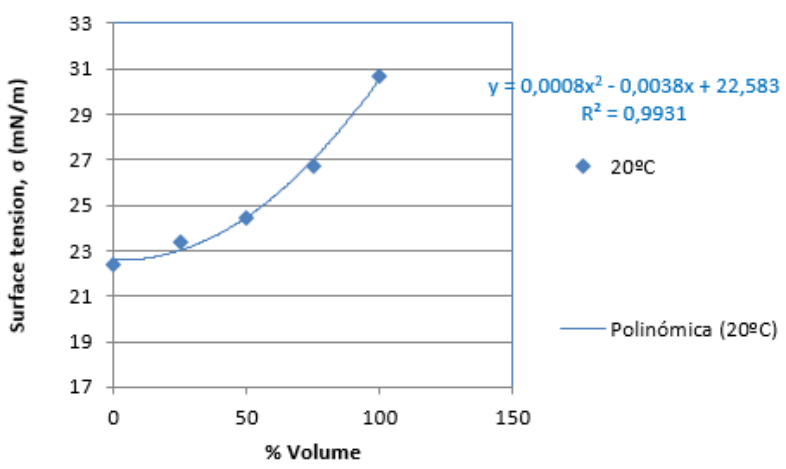

Fig. 6. Surface tension $(\mathrm{mN} / \mathrm{m})$ VS percentage by volume of biodiesel in the blend.

\section{Conclusions}

It was corroborated that density is proportional to the concentration of each pure fuel in the blend. Density increases linearly as the concentration of biodiesel in ethanol increases.

We consider that the most important fuel property to be experimentally obtained is surface tension, due to the lack of literature information.

In view of the results obtained, the surface tension of biodiesel-ethanol blends increases by increasing the concentration of biodiesel in ethanol. Nevertheless, this increment is not lineal. Surface tension fits a second-order polynomial.

\section{Acknowledgement}

This work was supported by the Spanish Ministry of Science, Innovation and Universities [RTI2018-095923-BC21].

\section{References.}

[1] A. Murovskaya, Z. Sapronova and S. Murovskiy, "Influence of vehicles on pollution of atmospheric air of seaside towns". Teka Komisji Motoryzacji i Energetyki Rolnictwa (2011). Vol 11, pp. 73-81.

[2] M. Nesbit, M Fergusson, A. Colsa, J. Ohlendorf, C. Hayes, K. Paquel, JP. Schweitzer. "Comparative study on the differences between the EU and US legislation on emissions in the automotive sector". Policy department. Economic and scientific policy. European Parliament (2016). IP/A/EMIS/2016-02, PE 587.331.

[3] E. Torres-Jiménez, O. Armas, L. Lesnikand F. Cruz-Peragón. "Methodology to simulate normalized testing cycles for engines and vehicles via design of experiments with low number of runs". Energy Conversion and Management (2018). Vol. 177, pp. 817-832.

[4] P. Gadonneix, et al, Global Transport Scenarios 2050, World Energy Council, London (2011), pp. 1-74.

[5] N. Watson, A. Pilley and M. Marzouk, "A combustion correlation for diesel engine simulation". SAE Technical Paper (1980).

[6] K. Song-Charng, H. Zhiyu and R. Rolf D, "The development and application of a diesel ignition and combustion model for multidimensional engine simulation". SAE Technical Paper (1995). Vol 104, pp. 502-518.
[7] E. Torres-Jimenez, M. Kegl, R. Dorado and B. Kegl, "Numerical injection characteristics analysis of various renewable fuel blends". Fuel (2012). Vol. 97, pp. 832-842

[8] B. Vajda, L. Lešnik, G. Bombek, I. Biluš, Z. Žunič, L. Škerget and B. Kegl, "The numerical simulation of biofuels spray”. Fuel (2015). Vol 144, pp. 71-79.

[9] L. Lešnik, B. Vajda, Z. Žunič, L. Škerget and B. Kegl, "The influence of biodiesel fuel on injection characteristics, diesel engine performance, and emission formation". Applied energy (2013). Vol 111, pp. 558-570.

[10] A. Konstandopoulos, M. Kostoglou, N. Vlachos, and E. Kladopoulou, "Progress in Diesel Particulate Filter Simulation," SAE Technical Paper (2005).

[11] E. de Villiers, A. D. Gosman and H. G. Weller, "Large eddy simulation of primary diesel spray atomization," SAE Transactions (2004). Vol 113, pp 193-206

[12] M.M. Hasan, M.M. Rahman. "Performance and emission characteristics of biodiesel-diesel blend and environmental and economic impacts of biodiesel production: A review". Renewable and Sustainable Energy Reviews (2017). Vol. 74, pp. 938-948.

[13] Alan. C. Hansen, Q. Zhang, Peter W.L. Lyne. "Ethanoldiesel fuel blends - a review". Bioresource technology (2005). Vol. 96, no 3, pp. 277-285.

[14] M. Gülüm, A. Bilgin. "Density, flash point and heating value variations of corn oil biodiesel-diesel fuel blends". Fuel Processing Technology (2015). Vol. 134, pp. 456-464.

[15] L.M. Welsh, R.A. Davis. "Density and Viscosity of Aqueous Blends of N-Methyldiethanolamine and 2-Amino2-methyl-1-propanol". Journal of Chemical and Engineering (1995). Vol. 40, no 1, pp. 257-259.

[16] https://www.kruss-

scientific.com/products/tensiometers/force-tensiometer$\underline{\mathrm{k} 20 /}$

[17] A. Bhattarai, A.K. Yadav, S.K. Sah and A. Deo. "Influence of methanol and dimethyl sulfoxide and temperature on the micellization of cetylpyridinium chloride". Journal of Molecular Liquids (2017). Vol. 242, pp. 831-837. 